\title{
Recent advances in oxygenase-catalyzed biotransformations
}

Vlada B. Urlacher, Rolf D. Schmid

\section{Address}

Institute for Technical Biochemistry, University of Stuttgart, Allmandring 31,

D-70569 Stuttgart, Germany

Tel: (+49)-711- 685-3192

Fax:(+49)-711-685-4569

e-mail: Rolf.D.Schmid@itb.uni-stuttgart.de

\section{Summary}

Oxygenases continue to be widely studied for selective biooxidation of organic compounds. Protein engineering has resulted in heme and flavin monooxygenases with widely altered substrate specificities, and attempts have been reported to scale up reactions catalyzed by these enzymes. Cofactor regeneration is still a key issue in these developments. Protein engineering contributed to understanding of structure vs. function in dioxygenases.
Abbreviations
CYP102A1 (P450 BM-3) cytochrome P450 monooxygenase from Bacillus megaterium
CYP101 cytochrome P450 monooxygenase from Pseudomonas putida
FAD flavin adenine dinucleotide
ee $\quad$ enantiomeric exces
BVMO Baeyer-Villiger monooxygenase(s)
CHMO cyclohexanone monooxygenase 
styrene monooxygenase (StyAB) from Pseudomonas sp.

$$
\text { VLB120 }
$$

HbpA

2-hydroxybiphenyl-3-monooxygenase from Pseudomonas

azelaica HBP1

DDO

2,4-dinitrotoluene dioxygenase from Burkholderia cepacia R34

\section{Introduction}

Oxygenases are enzymes which introduce one or two atoms of molecular oxygen into an organic molecule. They are attractive for chemical synthesis and bioremediation as they react with a wide range of organic substances (Figure 1). Moreover, oxygenases may be enantio-, chemo- or regioselective and thus can produce optically pure compounds in reactions where chemical catalysts fail. Herein we focus on key papers on oxygenases, published over the past two years, which emphasize practical applications. A number of other reviews in this area have recently been published $\left[1,2,{ }^{*} 3\right]$.

Oxygenases are being exploited in various industrial processes [1]. Compared to other industrial enzymes such as hydrolases or isomerases, however, their practical applications are still limited. The major reasons are that most oxygenases are membrane-associated, often not very stable, displaying rather low activity. For their function, most oxygenases require reduction equivalents, which are usually supplied by NADPH or NADH. Besides, they need electron-transfer partners like e.g., flavin reductases and iron-sulfur proteins, which might be also membrane-associated.

Some of these limitations can be overcome by using whole-cell systems. Here, however, physiological effects such as low expression rates, limited substrate uptake, toxicity of substrate or product, and product degradation must be taken into account.

The mainstream of current studies is thus to either engineer isolated oxygenases for altered selectivity or enhanced stability, or to engineer the metabolism of whole cells towards 
improved yield of the desired oxidation product or to combine both approaches. This applies to hydroxylation and epoxidation reactions, Baeyer-Villiger oxidation and dihydroxylation biotransformation steps on which this review will be focused.

\section{Monooxygenases: cytochrome P450 monooxygenases}

Cytochrome P450 enzymes (CYPs) are heme-containing monooxygenases present in virtually all groups of living organisms. CYPs catalyze monooxygenation of hydrophobic compounds in the presence of $\mathrm{NAD}(\mathrm{P}) \mathrm{H}$ and are a potentially useful class of catalysts as they are able to introduce oxygen even at non-activated carbon-hydrogen bonds. As the repertoire of chemical reactions performed by CYPs is broad indeed, they have attracted considerable attention as potential biocatalysts. Eukaryotic CYPs are, however, membrane-associated and usually of low activity. These drawbacks have been addressed by many research groups [4]. Recent achievements in the co-expression of recombinant human CYPs with NADPH-dependent cytochrome P450 reductase in Escherichia coli [5,6], Yarrowia lipolytica [7] and Pichia pastoris [8] facilitates their preparative use for the synthesis of drug metabolites. For activity improvement, directed evolution has proven efficient again. For example, random mutagenesis of human CYP1A2 with subsequent screening using alkylresorufin as a model substrate allowed to construct and identify a mutant with a five-fold higher turnover number as compared to the native enzyme [9]. Plant CYPs may also offer potential for biotransformations. An excellent overview on this subject was published recently [10]. From a technical point of view, bacterial CYPs are easier to handle as they are often soluble enzymes. In addition, they are far more active than mammalian and plant CYPs. For example, the oxidative turnover of arachidonic acid by P450 BM-3 (CYP102A1) from Bacillus megaterium reaches $280 \mathrm{~s}^{-1}$ [11]. The high activity of this monooxygenase is believed to be due to its organization as a fusion protein, consisting of a heme-containing monooxygenase domain and a diflavin reductase domain. 
Recently, it was shown that CYP102A1 can be turned by protein design or directed evolution into an enzyme which oxidizes compounds of little or no structural similarity to fatty acids, its natural substrates $\left[12,13,14,{ }^{* * 15} 16\right]$. Replacement of phenylalanine 87 by valine not only greatly increased its activity towards phenolic compounds like 2,6-dichlorophenol and 2(benzyloxy)phenol, but also improved its regioselectivity eventually leading to only one product [12]. A new triple mutant, obtained by a combination of directed evolution and protein design, exhibited 80-fold higher activity toward $\beta$-ionone $\left(260 \mathrm{~min}^{-1}\right)$ compared to the wild type enzyme, producing the flavorant $(R)$-4-hydroxy- $\beta$-ionone ( $40 \%$ ee) as the only product. Coupling efficiency between NADPH oxidation and product formation was also improved [13]. A grapefruit flavor sesquiterpene, (+)-nootkatone, was produced from (+)valencene using mutants of CYP102A1 and CYP101 from Pseudomonas putida, respectively [17]. Although CYP102A1 mutants were more active in this reaction, they produced many side products and also oxidized the desired end product, (+)-noonkatone. Mutants of CYP101 had 4-fold lower reactions rates but were much more selective, forming $>85 \%$ of (+)-transnoonkatol and (+)-nootkatone.

Selective oxyfunctionalization of inert hydrocarbons is still a challenge for organic chemists. Arnold and co-workers combined several rounds of directed evolution with protein modeling and site-directed mutagenesis to alter the selectivity of CYP102A1 from hydroxylation of dodecane (C12) first to C8 (octane) and to C6 (hexane) and further on to C3 (propane) and C2 (ethane) $[* * 15,18,19]$. With an optimized reductase domain, a mutant capable to oxidize ethane to ethanol was obtained, showing, however, very low activity $\left(0.4 \mathrm{~min}^{-1}\right)$ and poor coupling efficiency $<1 \%$. Based on CYP101, another mutant capable of ethane hydroxylation was obtained [**20]. To this end, a step-by-step reduction of the enzyme's substrate binding pocket was done by site-directed mutagenesis, resulting in increased activity towards lower alkanes. The best mutant contained nine mutations and oxidized ethane to ethanol at a rate of $78 \mathrm{~min}^{-1}$, with $10.5 \%$ coupling efficiency. 
In view of the preparative use of isolated CYP102A1 or mutants of this enzyme, several attempts were undertaken to scale reactions up. Thus, CYP102A1 was used for the preparation of 15(R),16(S)-epoxyoctadeca-9,12-dienoic acid (60\% ee) from linolenic acid (Figure 2) [21]. Under the chosen reaction conditions the enzyme was highly regioselective and showed a high turnover rate of app. $3100 \mathrm{~min}^{-1}$.

The behavior of isolated CYP102A1 in a biphasic cyclohexane-water reaction system supported by cofactor recycling with an $\mathrm{NADP}^{+}$-dependent formate dehydrogenase has also been investigated [**22]. If stabilizing factors such as BSA and catalase were used, the enzyme stayed active longer than $100 \mathrm{~h}$, producing cyclohexanol as the single product. Stability and productivity of the monooxygenase mutants in biphasic systems was surprisingly high, as revealed by total turnover numbers of up to 12850 in NADPH-dependent cyclohexane hydroxylation. Using site-directed mutagenesis, the reductase domain of CYP102A1 was engineered to accept NADH with a similar performance [**22]. The NADHdependent mutant demonstrated high coupling efficiency (up to 60\%) and high stability under chosen reaction conditions. Using this mutant for myristic acid hydroxylation, volumetric productivity reached $150 \mathrm{mg} \mathrm{l}^{-1} \mathrm{~h}^{-1}$.

\section{Non-heme monooxygenases}

Non-heme monooxygenases are flavin-containing enzymes. Like P450 monooxygenases they require for activity $\mathrm{NAD}(\mathrm{P}) \mathrm{H}$. Protein engineering was used to modify enzyme activity, specificity and stability of non-heme monooxygenases. Thus, a new styrene monooxygenase (StyAB) from Pseudomonas sp. VLB120 catalyzed the specific (S)-epoxidation of a broad range of $m$ - and $p$ - as well as $\alpha$ - and $\beta$-substituted styrene derivatives [23]. The two component system, composed of an FAD-dependent monooxygenase (Sty A) and an NADH dependent reductase (Sty B), was expressed in E. coli, purified and used for cell-free epoxidation. NADH was regenerated in situ using formate and formate dehydrogenase [24]. 
Alternatively, direct regeneration of $\mathrm{FADH}_{2}$ using an artificial redox system [Cp*Rh(bpy)$\left.\left(\mathrm{H}_{2} 0\right)\right]^{+2}$, which can be reduced in presence of formate, was also achieved [*25]. The efficiency of the chemoenzymatic system reached $30-70 \%$ of the enzymatic system. The correct amount of FAD minimizing production of the catalytically inactive oxidized rhodium complex, is crucial for high efficiency of the system.

Chemoenzymatic epoxidation was then turned into electroenzymatic process using a cathode for primary electron supply, demonstrating that direct electrochemical regeneration of a flavin-dependent monooxygenase for catalysis is feasible [26]. An advantage of this system is a recyclability and robustness of $\left[\mathrm{Cp} * \mathrm{Rh}(\mathrm{bpy})-\left(\mathrm{H}_{2} 0\right)\right]^{+2}$ that is able to regenerate not only flavin-based cofactors, but also NADH. However, efficiency of the electroenzymatic system is not sufficient for a technical process and has to be optimized.

Another non-heme monooxygenase, 2-hydroxybiphenyl-3-monooxygenase (HbpA) from Pseudomonas azelaica HBP1, was engineered by directed evolution to accept a broad range of 2-substituted phenols [27]. The best mutant enzymes cloned into E. coli JM101 host cells were used for production of 3-tert-butylcatechol, a costly synthone for pharmaceuticals and dye developers. The product was removed in situ by Amberlite ${ }^{\mathrm{TM}}$ XAD-4, thus preventing degradation of the product. Volumetric productivity of the process reached $63 \mathrm{mg} \mathrm{l}^{-1} \mathrm{~h}^{-1}$. Baeyer-Villiger monooxygenases (BVMO) are an important group of enzymes among flavindependent non-heme monooxygenases. The chemical conversion of ketones into esters or cyclic ketones into lactones was discovered more than a century ago and, due to the mild reaction conditions, is still an attractive process for the preparation of flavors, fragrances and chemical intermediates. As a consequence, Baeyer-Villiger monooxygenases are studied intensively [28-31].

The best studied BVMO is cyclohexanone monooxygenase (CHMO) from Acinetobacter sp. NCIB 9871 [32]. It is now commercially available and has been used for production of bicyclic lactones [33], sulfoxides [34], thiosulfinates [35] and cyclic sulfates [36]. CHMO 
expressed in E. coli has also been used for dynamic kinetic resolution of racemic benzyloxymethyl-cyclopentanone under in situ racemization catalyzed by a weakly basic anion exchanger (Figure 3) [37]. Yields in preparative scale reactions were up to $84 \%$ of almost enantiopure $(R)$-enantiomer (97\% ee).

A whole-cell biocatalyst based on CHMO from Acinetobacter calcoaceticus NCIMB 9871 was used for oxidation of (-)-bicyclo[3.2.0]hept-2-ene-6-one [**29]. Resin-based in situ substrate feeding and product removal were essential to perform an asymmetric BaeyerVilliger oxidation on preparative scale. The process was further used to synthesize kilogram amounts of regioisomeric enantiopure lactones in a 50 L bioreactor [*30].

Directed evolution has been successfully applied to extend the substrate spectrum and enantioselectivity of this monooxygenase [*38,39]. In oxidation of prochiral 4hydroxycyclohexanone, some CHMO mutants showed improved enantioselectivity, favoring the $(R)$-enantiomer (49-54\% ee vs. 9\% ee for the wild type enzyme). Other variants showed inverted preference for the $(S)$-enantiomer $(79 \%$ ee) [*38]. This approach can be combined with an automated whole-cell process evaluation at the micro-scale, where substrate specificity, specific activity and selectivity of recombinant BMVO have been optimized using 96-well deep microtiter plate [40].

\section{Dioxygenases}

Dioxygenases are a heterogeneous group of enzymes capable of introducing two oxygen atoms at a double bond. So-called Rieske dioxygenases are non-heme iron-containing $\mathrm{NAD}(\mathrm{P}) \mathrm{H}$ dependent enzymes important in the biosynthesis of secondary metabolites such as flavonoids and alkaloids and in performing a key step in the natural degradation of aromatic compounds [41-43]. Rieske dioxygenases are multi-component systems, consisting of an oxygenase component, an iron-sulfur flavoprotein reductase and iron-sulfur ferredoxin. A 
number of publications describing the role of dioxygenases for bioremediation and biocatalysis have been published recently [44-47].

The best studied dioxygenases are naphthalene and toluene dioxygenase, although the number of novel dioxygenases is increasing [48,49]. Recently, recombinant E. coli JM101 cells producing the chlorobenzene dioxygenase from Pseudomonas sp. strain P51, were used for the cis-dihydroxylation of various aromatic nitriles [*50]. The productivity of the process, limited by product toxicity was increased by $43 \%$ by using an external charcoal column for product removal. Biotransformations resulted in products with 42,9-97,1\% ee.

Site-directed mutagenesis have been used to expand the substrate range and to increase activity of the 2,4-dinitrotoluene dioxygenase (DDO) from Burkholderia cepacia R34 [51]. Several mutants with high activity towards substituted phenols for production of catechols and hydroquinones were obtained. DNA-shuffling combined with saturation mutagenesis allowed also to construct mutants of naphthalene dioxygenase from Ralstonia sp. strain U2 which produced, for example, 3-amino-4-methyl-5-nitrocatechol and 2-amino-4,6dinitrobenzyl alcohol from 2-amino-4,6-dinitrotoluene, while the wild type dioxygenase has no detectable activity on this substrate [52].

\section{Conclusions}

At present, there is considerable effort to render isolated oxygenases useful for biotransformations. Protein engineering, enzyme stabilization and cofactor regeneration are key issues addressed in these studies. The use of engineered oxygenases in metabolically engineered whole cells has been less pronounced recently but might become fashionable again once the foundations for synthetic biology have become more advanced, e. g. by providing suitable host cells with engineered genomes. 


\section{Update}

Recent work has demonstrated that the bacterial cytochrome P450 fatty acid hydroxylase CYP102A1 can be engineered to produce the authentic human metabolites of propranolol in a reaction driven by hydrogen peroxide [*53]. An advantage of this system is its independence from NADPH and cofactor-recycling systems.

\section{Acknowledgements}

We thank our colleagues for fruitful discussions.

\section{References and recommended reading}

Papers of particular interest, published within the annual period of review, have been highlighted as:

*of special interest

**of outstanding interest

1. Schmid A, Dordick JS, Hauer B, Kiener A, Wubbolts M, Witholt B: Industrial biocatalysis today and tomorrow. Nature 2001, 409:258-268.

2. van Beilen JB, Duetz WA, Schmid A, Witholt B: Practical issues in the application of oxygenases. Trends Biotechnol 2003, 21:170-177.

*3. Buhler B, Schmid A: Process implementation aspects for biocatalytic hydrocarbon oxyfunctionalization. J Biotechnol 2004, 113:183-210.

A new review summarizes recent advances in the in vivo application of oxygenases. Critical aspects like low enzyme activity, low enzyme expression rates, product degradation and others are discussed. Authors give some interesting process examples from industry and academia.

4. Guengerich FP: Cytochrome P450 enzymes in the generation of commercial products. Nat Rev Drug Discov 2002, 1:359-366. 
5. Breinholt VM, Rasmussen SE, Brosen K, Friedberg TH: In vitro metabolism of genistein and tangeretin by human and murine cytochrome P450s. Pharmacol Toxicol 2003, 93:14-22.

6. Vail RB, Homann MJ, Hanna I, Zaks A: Preparative synthesis of drug metabolites using human cytochrome P450s 3A4, 2C9 and 1A2 with NADPH-P450 reductase expressed in Escherichia coli. J Ind Microbiol Biotechnol 2005, 32:67-74.

7. Nthangeni MB, Urban P, Pompon D, Smit MS, Nicaud JM: The use of Yarrowia lipolytica for the expression of human cytochrome P450 CYP1A1. Yeast 2004, 21:583-592.

8. Dietrich M, Grundmann L, Kurr K, Valinotto L, Saussele T, Schmid RD, Lange S: Recombinant production of human microsomal cytochrome P450 2D6 in the methylotrophic yeast Pichia pastoris. Chembiochem 2005, 6:2014-2022.

9. Kim D, Guengerich FP: Enhancement of 7-methoxyresorufin O-demethylation activity of human cytochrome P450 1A2 by molecular breeding. Arch Biochem Biophys 2004, 432:102-108.

10. Morant M, Bak S, Moller BL, Werck-Reichhart D: Plant cytochromes P450: tools for pharmacology, plant protection and phytoremediation. Curr Opin Biotechnol 2003, 14:151-162.

11. Munro AW, Leys DG, McLean KJ, Marshall KR, Ost TW, Daff S, Miles CS, Chapman SK, Lysek DA, Moser CC, et al.: P450 BM3: the very model of a modern flavocytochrome. Trends Biochem Sci 2002, 27:250-257.

12. Sulistyaningdyah WT, Ogawa J, Li QS, Maeda C, Yano Y, Schmid RD, Shimizu S: Hydroxylation activity of P450 BM-3 mutant F87V towards aromatic compounds and its application to the synthesis of hydroquinone derivatives from phenolic compounds. Appl Microbiol Biotechnol 2005, 67:556-562.

13. Urlacher VB, Makhsumkhanov A, Schmid RD: Biotransformation of beta-ionone by engineered cytochrome P450 BM-3. Appl Microbiol Biotechnol 2005:1-7. 
*14. Munzer DF, Meinhold P, Peters MW, Feichtenhofer S, Griengl H, Arnold FH, Glieder A, de Raadt A: Stereoselective hydroxylation of an achiral cyclopentanecarboxylic acid derivative using engineered P450s BM-3. Chem Commun (Camb) 2005, 28:2597-9.

**15. Meinhold P, Peters MW, Chen MM, Takahashi K, Arnold FH: Direct conversion of ethane to ethanol by engineered cytochrome P450 BM3. Chembiochem 2005, 6:1765-1768.

CYP102A1 monooxygenase, an enzyme highly active in fatty acid subterminal oxidation, has been evolved, via directed evolution, into an ethane-hydroxylating enzyme.

16. Kubo T, Peters MW, Meinhold P, Arnold FH: Enantioselective Epoxidation of Terminal Alkenes to (R)- and (S)-Epoxides by Engineered Cytochromes P450 BM-3. Chemistry 2006, 12:1216-1220.

17. Sowden RJ, Yasmin S, Rees NH, Bell SG, Wong LL: Biotransformation of the sesquiterpene (+)-valencene by cytochrome P450cam and P450BM-3. Org Biomol Chem 2005, 3:57-64.

18. Glieder A, Farinas ET, Arnold FH: Laboratory evolution of a soluble, self-sufficient, highly active alkane hydroxylase. Nat Biotechnol 2002, 20:1135-1139.

19. Peters MW, Meinhold P, Glieder A, Arnold FH: Regio- and enantioselective alkane hydroxylation with engineered cytochromes P450 BM-3. J Am Chem Soc 2003, 125:13442-13450.

**20. Xu F, Bell SG, Lednik J, Insley A, Rao ZH, Wong LL: The heme monooxygenase cytochrome P450(cam) can be engineered to oxidize ethane to ethanol. Angewandte Chemie-International Edition 2005, 44:4029-4032.

A clever structure-based protein engineering approach which, by decreasing the size of the substrate binding pocket, turns camphor-selective CYP101 into a fairly active ethanehydroxylating enzyme. 
21. Celik A, Sperandio D, Speight RE, Turner NJ: Enantioselective epoxidation of linolenic acid catalysed by cytochrome P450(BM3) from Bacillus megaterium. Org Biomol Chem 2005, 3:2688-2690.

**22. Maurer SC, Kuhnel K, Kaysser LA, Eiben S, Schmid RD, Urlacher VB: Catalytic hydroxylation in biphasic systems using CYP102A1 mutants. Adv Synth Catal 2005, 347:1090-1098.

Isolated CYP102 mutant enzymes are able to transform cyclohexane or fatty acids in a biphasic system into cyclohexanol or hydroxyl fatty acids for several days, using NADH and formate dehydrogenase for cofactor regeneration after protein engineering of the reductase domain.

23. Schmid A, Hofstetter K, Feiten HJ, Hollmann F, Witholt B: Integrated biocatalytic synthesis on gram scale: The highly enantio selective preparation of chiral oxiranes with styrene monooxygenase. Adv Synth Catal 2001, 343:732-737.

24. Hofstetter K, Lutz J, Lang I, Witholt B, Schmid A: Coupling of biocatalytic asymmetric epoxidation with NADH regeneration in organic-aqueous emulsions. Angew Chem Int Ed Engl 2004, 43:2163-2166.

*25. Hollmann F, Lin PC, Witholt B, Schmid A: Stereospecific biocatalytic epoxidation: the first example of direct regeneration of a FAD-dependent monooxygenase for catalysis. J Am Chem Soc 2003, 125:8209-8217.

Styrene monooxygenase, a flavin-containing monooxygenase from Pseudomonas sp., forms chiral epoxides in good yields from a wide range of aromatic substrates such as styrol in the presence of a metal-organic mediator which can be regenerated by formate.

26. Hollmann F, Hofstetter K, Habicher T, Hauer B, Schmid A: Direct electrochemical regeneration of monooxygenase subunits for biocatalytic asymmetric epoxidation. J Am Chem Soc 2005, 127:6540-6541. 
27. Meyer A, Held M, Schmid A, Kohler HP, Witholt B: Synthesis of 3-tert-butylcatechol by an engineered monooxygenase. Biotechnol Bioeng 2003, 81:518-524.

28. Kamerbeek NM, Janssen DB, van Berkel WJH, Fraaije MW: Baeyer-Villiger monooxygenases, an emerging family of flavin-dependent biocatalysts. Adv Synth Catal 2003, 345:667-678.

*29. Hilker I, Gutierrez MC, Alphand V, Wohlgemuth R, Furstoss R: Microbiological transformations 57. Facile and efficient resin-based in situ SFPR preparativescale synthesis of an enantiopure "unexpected" lactone regioisomer via a BaeyerVilliger oxidation process. Org Lett 2004, 6:1955-1958.

Based on recombinant strains with overexpressed Baeyer-Villiger monooxygenase, reaction engineering is used to synthesize regioisomeric enantiopure lactones from a bicyclic ketone precursor in preparative scale

**30. Hilker I, Wohlgemuth R, Alphand V, Furstoss R: Microbial transformations 59: First kilogram scale asymmetric microbial Baeyer-Villiger oxidation with optimized productivity using a resin-based in situ SFPR strategy. Biotechnol Bioeng 2005.

The asymmetric microbial Baeyer-Villiger oxidation of a bicyclic ketone, decribed in article 29, was scaled up to the kilogram scale using a $50 \mathrm{~L}$ bioreactor. The process has been optimized with respect to bottlenecks identified in downscaled experiments.

31. Alphand V, Carrea G, Wohlgemuth R, Furstoss R, Woodley JM: Towards large-scale synthetic applications of Baeyer-Villiger monooxygenases. Trends Biotechnol 2003, 21:318-323.

32. Mihovilovic MD, Muller B, Stanetty P: Monooxygenase-mediated Baeyer-Villiger oxidations. Eur J Org Chem 2002:3711-3730.

33. Ottolina G, de Gonzalo G, Carrea G, Danieli B: Enzymatic Baeyer-Villiger oxidation of bicyclic diketones. Adv Synth Catal 2005, 347:1035-1040. 
34. Kamerbeek NM, Moonen MJ, Van Der Ven JG, Van Berkel WJ, Fraaije MW, Janssen DB: 4-Hydroxyacetophenone monooxygenase from Pseudomonas fluorescens ACB. A novel flavoprotein catalyzing Baeyer-Villiger oxidation of aromatic compounds. Eur J Biochem 2001, 268:2547-2557.

35. Colonna S, Del Sordo S, Gaggero N, Carrea G, Pasta P: Enzyme-mediated catalytic asymmetric oxidations. Heteroatom Chem 2002, 13:467-473.

36. Colonna S, Gaggero N, Carrea G, Pasta P: Oxidation of organic cyclic sulfites to sulfates: a new reaction catalyzed by cyclohexanone monooxygenase. Chem Commun 1998:415-416.

37. Gutierrez MC, Furstoss R, Alphand W: Microbiological transformations 60 . Enantioconvergent Baeyer-Villiger oxidation via a combined whole cells and ionic exchange resin-catalysed dynamic kinetic resolution process. Adv Synth Catal 2005, 347:1051-1059.

*38. Reetz MT, Brunner B, Schneider T, Schulz F, Clouthier CM, Kayser MM: Directed evolution as a method to create enantioselective cyclohexanone monooxygenases for catalysis in Baeyer-Villiger reactions. Angew Chem Int Ed Engl 2004, 43:40754078.

Using directed evolution and an automated GC screening on 10000 mutants, cyclohexanone monooxygenases with enantioselectivity exceeding $90 \%$ ee were screened.

39. Bocola M, Schulz F, Leca F, Vogel A, Fraaije MW, Reetz MT: Converting phenylacetone monooxygenase into phenylcyclohexanone monooxygenase by rational design: Towards practical Baeyer-Villiger monooxygenases. Adv Synth Catal 2005, 347:979-986.

40. Ferreira-Torres C, Micheletti M, Lye GJ: Microscale process evaluation of recombinant biocatalyst libraries: application to Baeyer-Villiger monooxygenase catalysed lactone synthesis. Bioprocess Biosyst Eng 2005, 28:83-93. 
41. Boyd DR, Sharma ND, Allen CC: Aromatic dioxygenases: molecular biocatalysis and applications. Curr Opin Biotechnol 2001, 12:564-573.

42. van der Geize R, Dijkhuizen L: Harnessing the catabolic diversity of rhodococci for environmental and biotechnological applications. Curr Opin Microbiol 2004, $7: 255-261$

43. Pieper DH: Aerobic degradation of polychlorinated biphenyls. Appl Microbiol Biotechnol 2005, 67:170-191.

44. Buckel W: On the road to bioremediation of "dioxin". Chem Biol 2005, 12:723-724.

45. Larkin MJ, Kulakov LA, Allen CC: Biodegradation and Rhodococcus--masters of catabolic versatility. Curr Opin Biotechnol 2005, 16:282-290.

46. Pollmann K, Wray V, Pieper DH: Chloromethylmuconolactones as critical metabolites in the degradation of chloromethylcatechols: recalcitrance of 2-chlorotoluene. $J$ Bacteriol 2005, 187:2332-2340.

47. Royo JL, Moreno-Ruiz E, Cebolla A, Santero E: Stable long-term indigo production by overexpression of dioxygenase genes using a chromosomal integrated cascade expression circuit. J Biotechnol 2005, 116:113-124.

48. Kim D, Chae JC, Zylstra GJ, Kim YS, Kim SK, Nam MH, Kim YM, Kim E: Identification of a novel dioxygenase involved in metabolism of o-xylene, toluene, and ethylbenzene by Rhodococcus sp. strain DK17. Appl Environ Microbiol 2004, 70:7086-7092.

49. Choi KY, Kim D, Koh SC, So JS, Kim JS, Kim E: Molecular cloning and identification of a novel oxygenase gene specifically induced during the growth of Rhodococcus sp. strain T104 on limonene. J Microbiol 2004, 42:160-162.

*50. Yildirim S, Franko TT, Wohlgemuth R, Kohler HPE, Witholt B, Schmid A: Recombinant chlorobenzene dioxygenase from Pseudomonas sp P51: A 
biocatalyst for regioselective oxidation of aromatic nitriles. Adv Synth Catal 2005, 347:1060-1072.

This publication is focused on preparative use of dioxygenase for cis-dihydroxylation of aromatic nitriles. The approach can enable the production of new synthones in significant yields.

51. Keenan BG, Leungsakul T, Smets BF, Wood TK: Saturation mutagenesis of Burkholderia cepacia R34 2,4-dinitrotoluene dioxygenase at DntAc valine 350 for synthesizing nitrohydroquinone, methylhydroquinone, and methoxyhydroquinone. Appl Environ Microbiol 2004, 70:3222-3231.

52. Keenan BG, Leungsakul T, Smets BF, Mori MA, Henderson DE, Wood TK: Protein engineering of the archetypal nitroarene dioxygenase of Ralstonia sp. strain U2 for activity on aminonitrotoluenes and dinitrotoluenes through alpha-subunit residues leucine 225, phenylalanine 350, and glycine 407. J Bacteriol 2005, 187:3302-3310.

*53. Otey CR, Bandara G, Lalonde J, Takahashi K, Arnold FH: Preparation of human metabolites of propranolol using laboratory-evolved bacterial cytochromes P450. Biotechnol Bioeng 2006, 93:494-499.

In this work, variants of CYP102A1 (P450 BM-3) were constructed and described, which are able to accept and convert propranolol, a multi-function beta-adrenergic blocker. Implementation of these variants would open up a cost-effective route to the production of different human metabolites. 
Legends to figures.

Figure 1. Typical reactions, catalyzed by oxygenases: (a) Hydroxylation by monooxygenase;

(b) Epoxidation by monoxygenase; (c) Baeyer-Villiger oxidation; (d) Dioxygenation by dioxygenase.

Figure 2. Enantioselective epoxidation of linolenic acid by CYP102A1 [21].

Figure 3. Dynamic kinetic resolution of racemic benzyl-oxymethyl-cyclopentanone using CHMO [37]. 
(a)

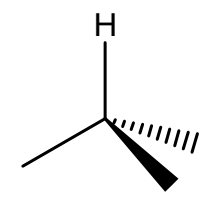

$\downarrow$

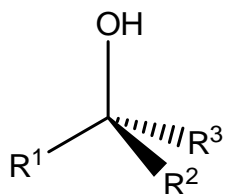

(b)
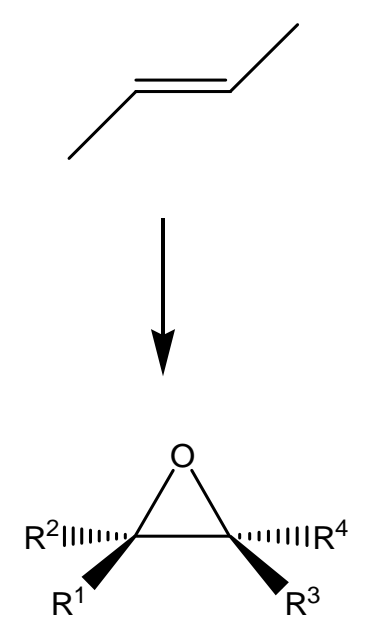

(c)
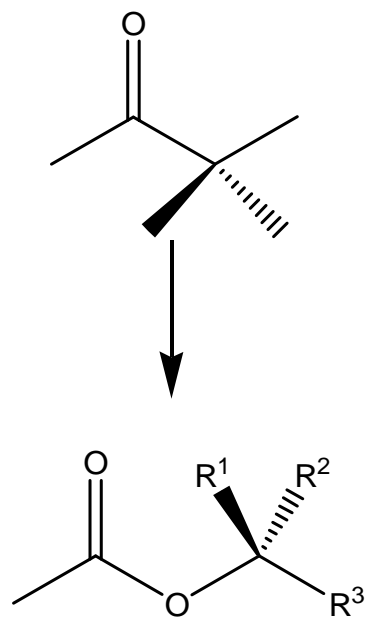

(d)<smiles>c1ccccc1</smiles>

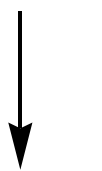<smiles>O[C@H]1C=CC=C[C@H]1O</smiles>

Figure 1.

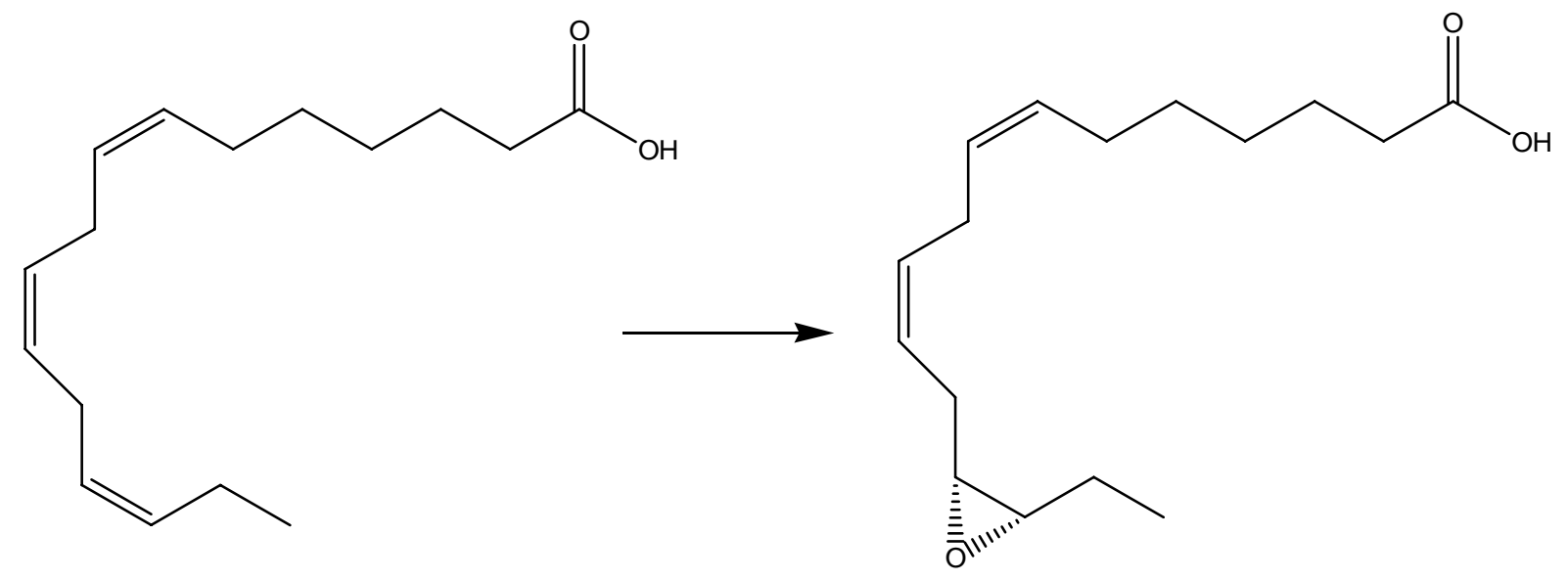


Figure 2.
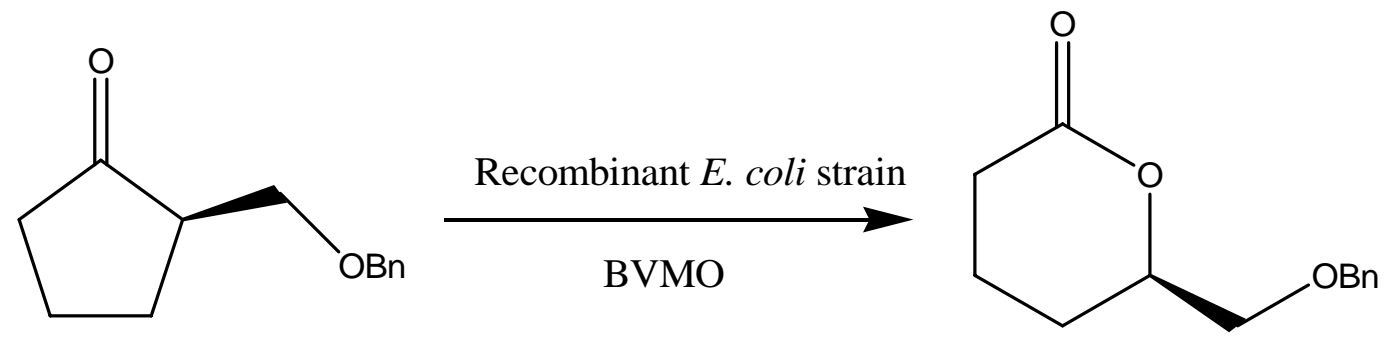

(R)-2-Benzyl-oxymethyl-cyclopentanone

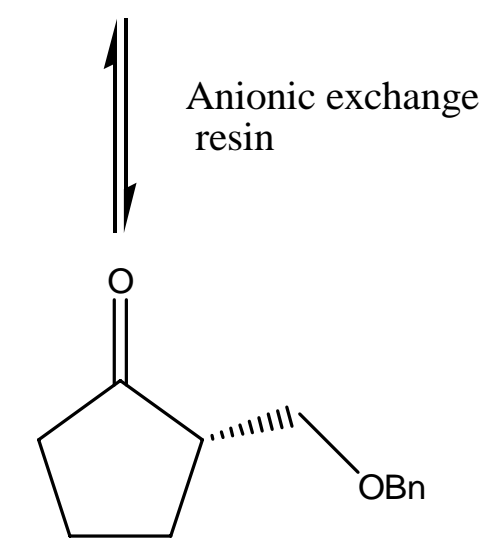

(S)-2-Benzyl-oxymethyl-cyclopentanone

Figure 3. 